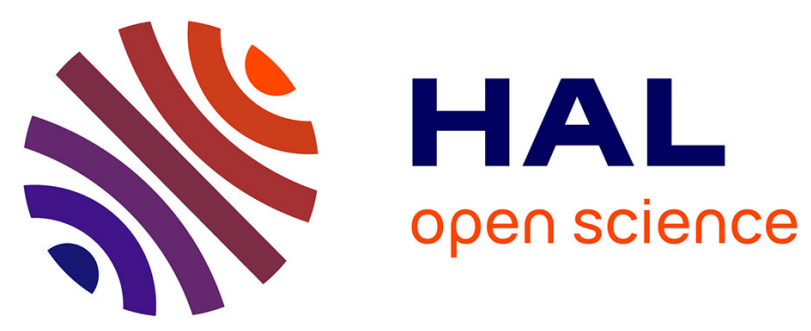

\title{
Fine Structure of the Gastrodermis of Two Species of Gyrodactylus (Monogenoidea: Polyonchoinea, Gyrodactylidae)'
}

\author{
Delane C. Kritsky, Denis Bourguet, Richard D. Spall
}

\section{To cite this version:}

Delane C. Kritsky, Denis Bourguet, Richard D. Spall. Fine Structure of the Gastrodermis of Two Species of Gyrodactylus (Monogenoidea: Polyonchoinea, Gyrodactylidae)'. Transactions of the American Microscopical Society, 1994, 113, pp.43 - 51. 10.2307/3226578 . hal-02914108

\section{HAL Id: hal-02914108 \\ https://hal.inrae.fr/hal-02914108}

Submitted on 11 Aug 2020

HAL is a multi-disciplinary open access archive for the deposit and dissemination of scientific research documents, whether they are published or not. The documents may come from teaching and research institutions in France or abroad, or from public or private research centers.
L'archive ouverte pluridisciplinaire HAL, est destinée au dépôt et à la diffusion de documents scientifiques de niveau recherche, publiés ou non, émanant des établissements d'enseignement et de recherche français ou étrangers, des laboratoires publics ou privés. 


\title{
Fine Structure of the Gastrodermis of Two Species of Gyrodactylus (Monogenoidea: Polyonchoinea, Gyrodactylidae)
}

\author{
Delane C. Kritsky, ${ }^{2}$ Denis Bourguet, ${ }^{2,3}$ and Richard D. Spall ${ }^{4}$ \\ ${ }^{2}$ College of Health Professions, Idaho State University, Pocatello, Idaho 83209, U.S.A., \\ ${ }^{3}$ Institut des Sciences de l'Evolution, Laboratoire Génétique et Environnement, \\ Université Montpellier II, Place Eugène Bataillon, 34095 Montpellier cedex 5, France, and \\ ${ }^{+}$Department of Biological Sciences, Idaho State University, Pocatello, Idaho 83209, U.S.A.
}

\begin{abstract}
Transmission electron microscopy was used to determine the organization and fine structure of the gastrodermis of two species of Gyrodactylus. The gastrodermis consists of a syncytial epithelium characterized by large widely spaced nuclei, two types of vesicular structures, mitochondria with tubular cristae, Golgi complexes, and scattered rough endoplasmic reticulum; the luminal surface possesses few widely spaced, branched lamellae projecting into the intestinal lumen. Organization of the gastrodermis in the Monogenoidea is discussed; the syncytial gastrodermis is considered to be a possible synapomorphic feature of the Gyrodactylidea.
\end{abstract}

Two general patterns of nutrition occur within the Monogenoidea (see Halton \& Jennings, 1965). In the subclass Polyonchoinea, member species usually feed on epidermal tissues and secretions of the host, and species of the subclasses Polystomatoinea and Oligonchoinea are generally sanguinivorous. These nutritional preferences appear to be related to gastrodermal structure and organization. In the Polystomatoinea and Oligonchoinea, the gut wall is comprised of two cell types, one of which is involved in digestion of blood (see Rohde, 1980, for review). In polyonchoinean species investigated to date, the gastrodermis comprises a monolayer of cells consisting of a single cell type (Fournier, 1978; Halton \& Stranock, 1976; Junchis, 1988). Apparently, the latter organization of the gastrodermis is symplesiomorphic for the Monogenoidea in that a similar state also occurs among rhabdocoel turbellarians (Holt \& Mettrick, 1975) as well as among some digeneans and aspidobothreans (Dike, 1967; Hathaway, 1972; Rohde, 1971). The purpose of this paper is to report an apomorphic state of the gastrodermis within the derived polyonchoinean family Gyrodactylidae.

\section{Materials and MEthods}

Specimens of Gyrodactylus eucaliae Ikezaki \& Hoffman, 1957 and Gyrodactylus sp. were collected from the skins of Culaea inconstans (Kirtland) in Illinois and Rhinichthys osculus (Girard) in Idaho, respectively. Preparatory procedures of G. eucaliae for electron microscopy were presented by Kritsky \& Kruidenier (1976). Specimens of Gyrodactylus sp. were fixed at $0^{\circ} \mathrm{C}$ for $4 \mathrm{~h}$ in a solution of equal parts of $1.5 \%$ paraformaldehyde and $1.5 \%$ glutaraldehyde buffered at $7.3 \mathrm{pH}$ with $0.1 \mathrm{M}$ sodium cacodylate. After postfixation in buffered $1 \% \mathrm{OsO}_{4}$ for $20 \mathrm{~min}$, the worms were washed in distilled water and dehydrated

' The authors are grateful to Mr. Jim Smothers, Department of Biological Sciences, Idaho State University, for assistance in the electron-microscope laboratory. 


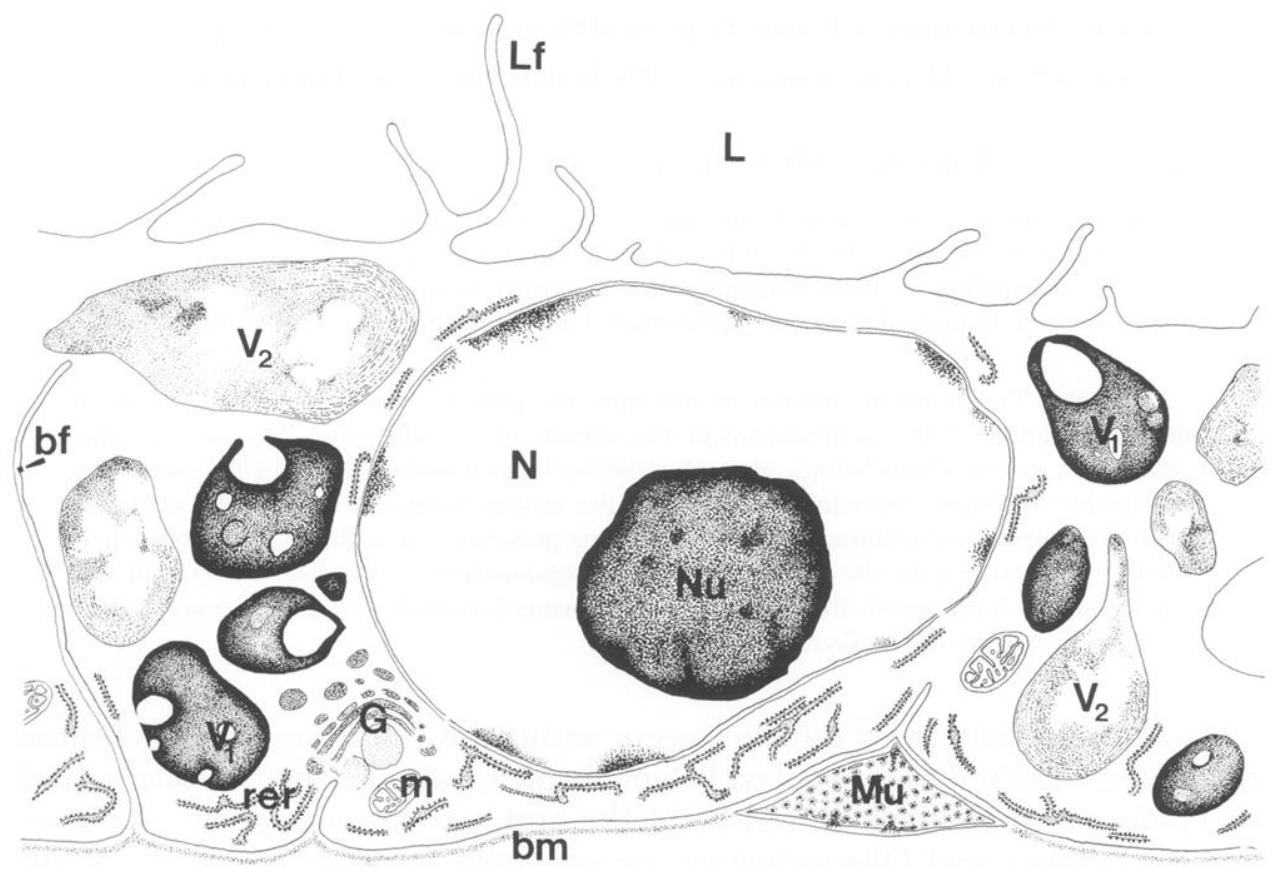

FIc: 1. Diagram of the gastrodermal ultrastructure of Gyrodactylus spp. bf, basal fold; bm, basal matrix; G, Golgi complex; L, lumen; Lf, luminal fold; m, mitochondrion; Mu, muscle; N, nucleus; $\mathrm{Nu}$, nucleolus; rer, rough endoplasmic reticulum; $\mathrm{V}_{1}, \mathrm{~V}_{2}$, cytoplasmic vesicles.

through a graded ethanol series. Helminths were embedded from propylene oxide into Spurr's epoxy resin modified by substitution of Quetol 651 for DER 736 (all components available through Polysciences, Inc., Warington, Pennsylvania); polymerization was at $50-60^{\circ} \mathrm{C}$. Thin sections were double-stained in alcoholic uranyl acetate and lead citrate. Sections were examined with a Zeiss 900 electron microscope at $80 \mathrm{kV}$.

\section{RESULTS}

In both Gyrodactylus eucaliae and Gyrodactylus sp., the wall of the esophagus and of the intestinal ceca consisted of an uninterrupted syncytial gastrodermis resting on a fibrous, 500-600 ̊-thick basal matrix in which widely spaced longitudinal and circular muscles, each approximately $1.0 \mu \mathrm{m}$ in $\mathrm{di}$ ameter, occurred (Figs. 1, 2). Apparently, partitioning of the gastrodermis was incomplete throughout resulting from deep infoldings of the basal plasmalemma (Fig. 3). A septate junction joined the epithelial lining of the pharynx to the gastrodermis in the esophagus (Fig. 4).

The luminal surface was limited by a 70 - $\AA$ unit membrane; scattered lamellae projected about $0.5 \mu \mathrm{m}$ from the surface into the lumen (Fig. 5). These lamellae were occasionally branched secondarily, but none were observed to recurve and rejoin the gastrodermal surface. Evidence of phagocytic activity was not apparent, although vesicles containing material similar to that contained in the lumen of the gut were occasionally present within the gastrodermis. 


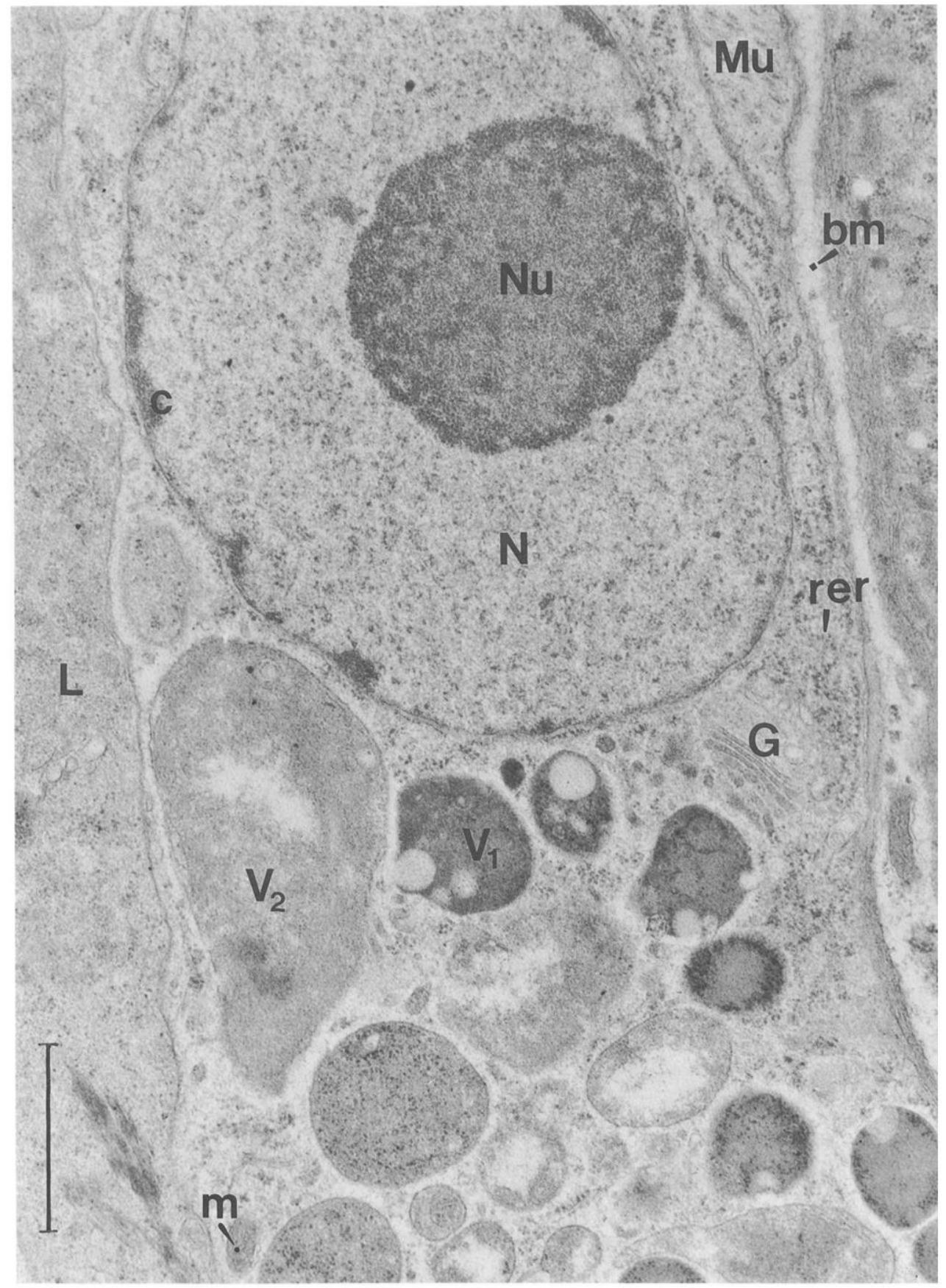

FIG. 2. Gastrodermis of Gyrodactylus eucaliae showing a typical nucleus (N) with enclosed nucleolus $(\mathrm{Nu})$, heterochromatin (c), and granular nucleoplasm. The cytoplasm is characterized by rough endoplasmic reticulum (rer), a Golgi complex $(\mathrm{G})$, and two types of cytoplasmic vesicles $\left(\mathrm{V}_{1}\right.$, $\mathrm{V}_{2}$ ). bm, basal matrix; $\mathrm{L}$, intestinal lumen; $\mathrm{m}$, mitochondrion; $\mathrm{Mu}$, muscle. Scale bar represents $1 \mu \mathrm{m}$. 


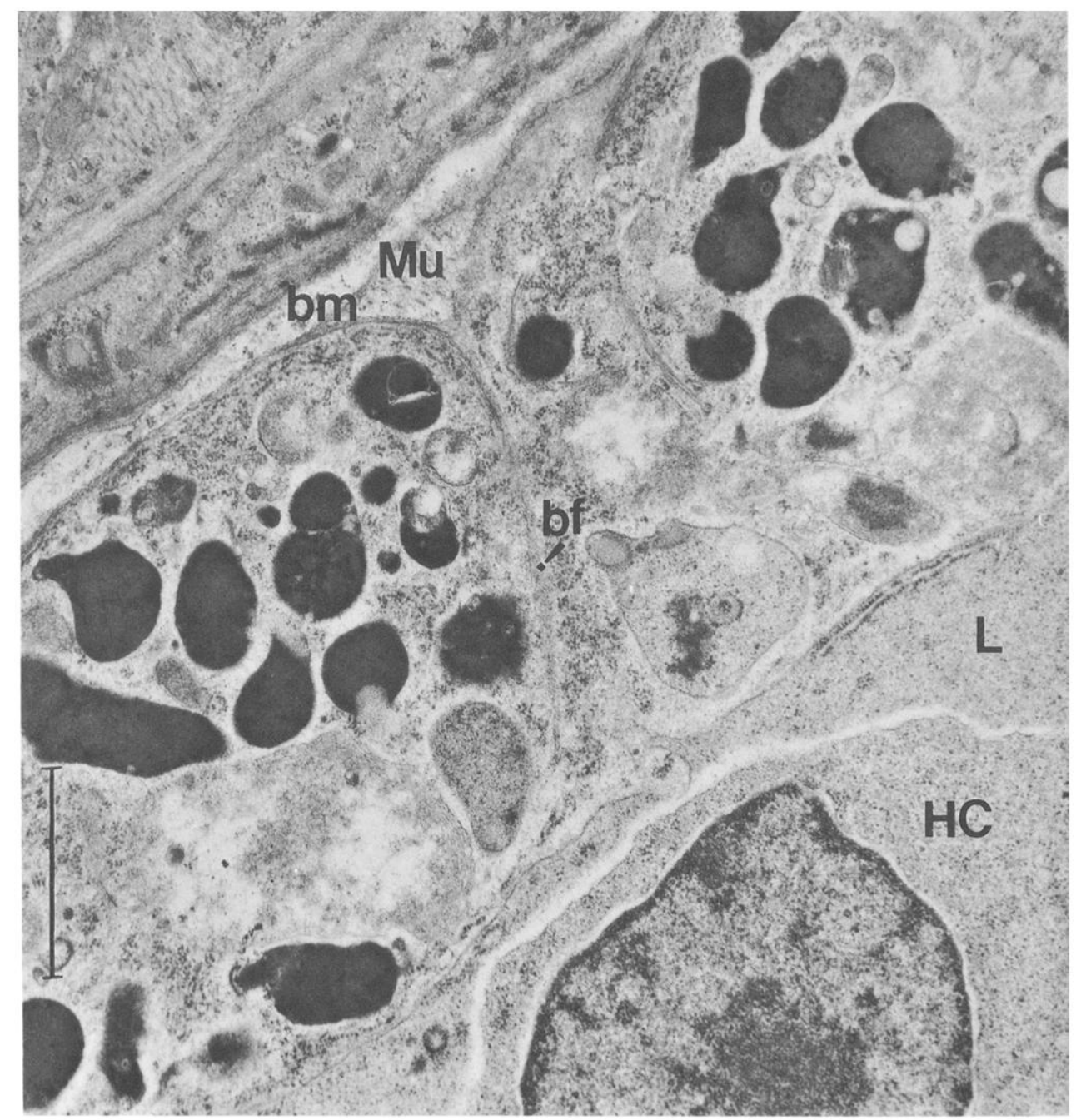

FIG. 3. Gastrodermis of Gyrodactylus eucaliae showing deep infoldings (bf) of the basal plasmalemma. Note the small basal muscle (Mu) and a presumed engulfed host cell (HC) in the intestinal lumen $(\mathrm{L})$. bm, basal matrix. Scale bar represents $1 \mu \mathrm{m}$.

The gastrodermis was provided with large, spherical to ovate, widely dispersed nuclei that extended from near the basal membrane almost to the luminal surface. Each was provided with a large, spherical nucleolus near its center or in contact with a typical nucleolemma. A thin layer of heterochromatin occurred within the finely granular nucleoplasm just beneath the nucleolemma (Fig. 2).

Vesicles, apparently of two types $\left(\mathrm{V}_{1}\right.$ and $\left.\mathrm{V}_{2}\right)$, dominated the contents of the gastrodermis of both species of Gyrodactylus. The $\mathrm{V}_{1}$ vesicle was pyriform to subspherical, was bounded by an indistinct membrane ( $70 \AA$ thick), and contained electron-dense material in which lighter spherical chambers and small 


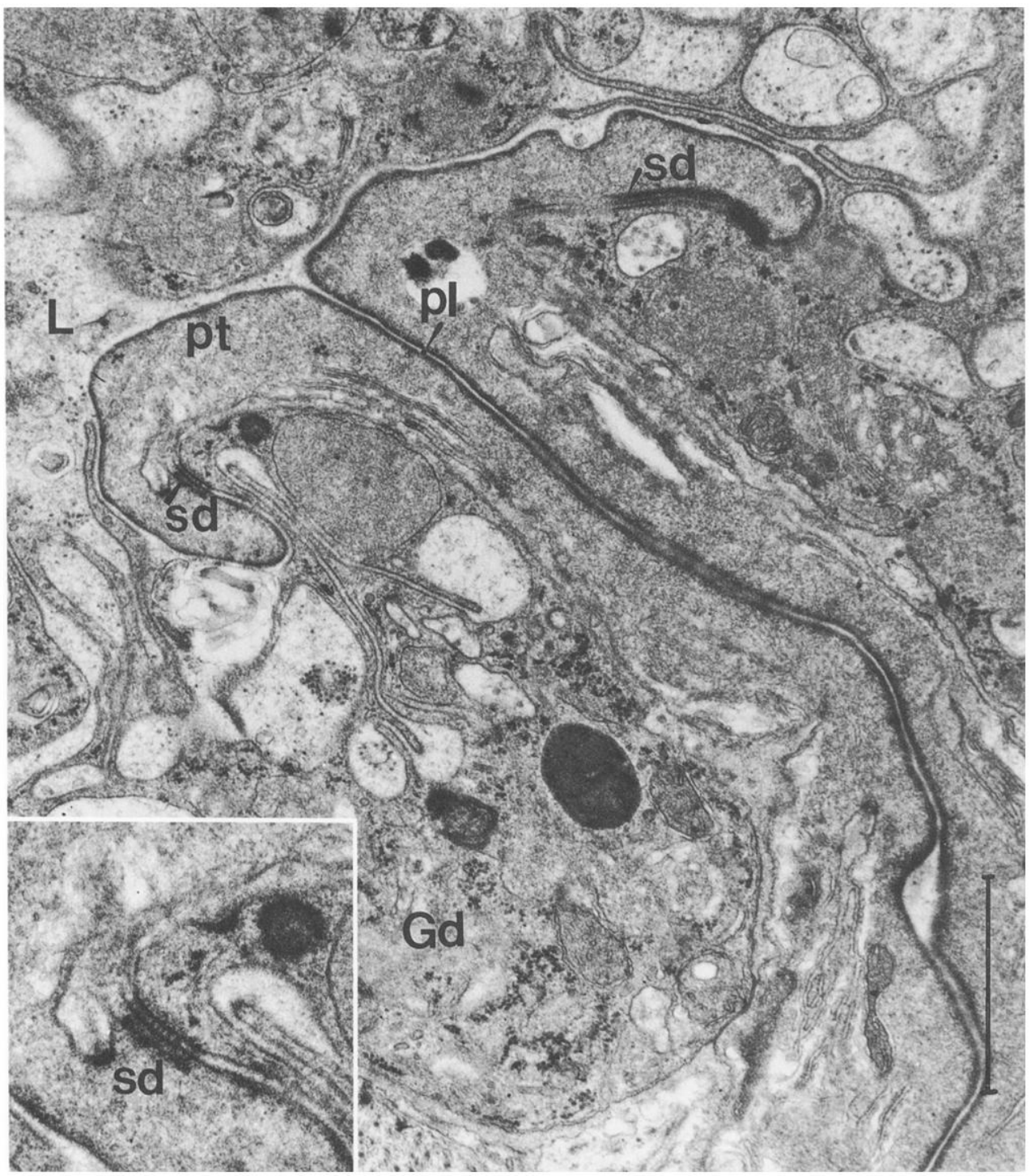

FIG. 4. Pharyngeal epithelium (pt) uniting with the gastrodermis $(\mathrm{Gd})$ in the esophagus of Gyrodactylus eucaliae. Note (inset) that the union is made by a septate junction (sd). L, intestinal lumen; pl, pharyngeal lumen. Scale bar represents $1 \mu \mathrm{m}$.

opaque granules, $180 \AA$ in diameter, were distributed; the chambers, containing a finely reticulate material, frequently appeared to release their contents into the gastrodermal cytoplasm (Figs. 2,3). Although $\mathrm{V}_{1}$ vesicles occurred throughout the gastrodermis, they tended to be most concentrated near the basal portion; they were less abundant in specimens with collapsed (starved?) lumens. The $\mathrm{V}_{2}$ vesicle consisted of a membrane-bounded, variably shaped unit with an 


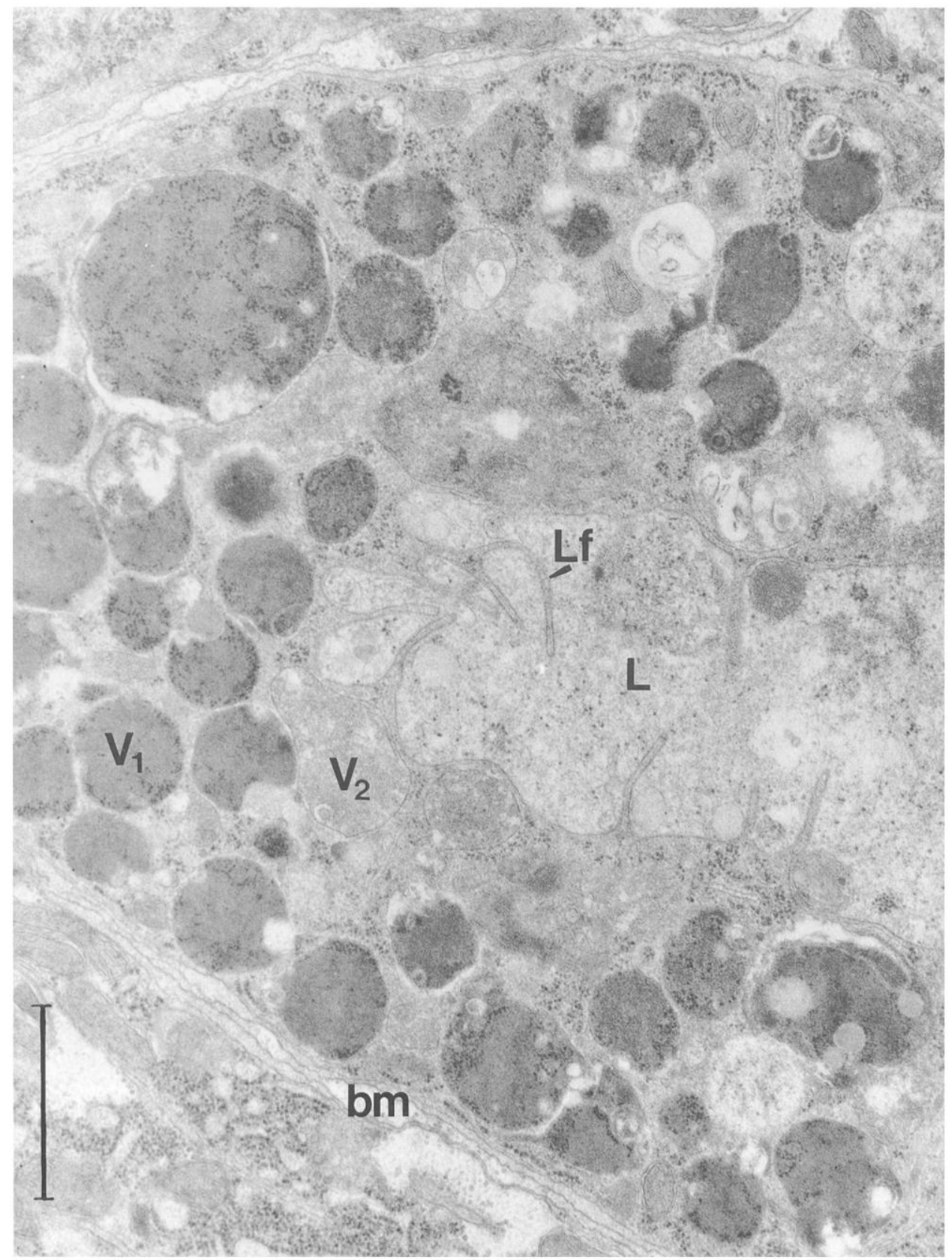

FIG. 5. Gastrodermis of Gyrodactylus eucaliae. Note cytoplasmic vesicles $\left(\mathrm{V}_{1}, \mathrm{~V}_{2}\right)$ and luminal folds (Lf) and their branching within the lumen (L) of the gut. bm, basal matrix. Scale bar represents $1 \mu \mathrm{m}$. 


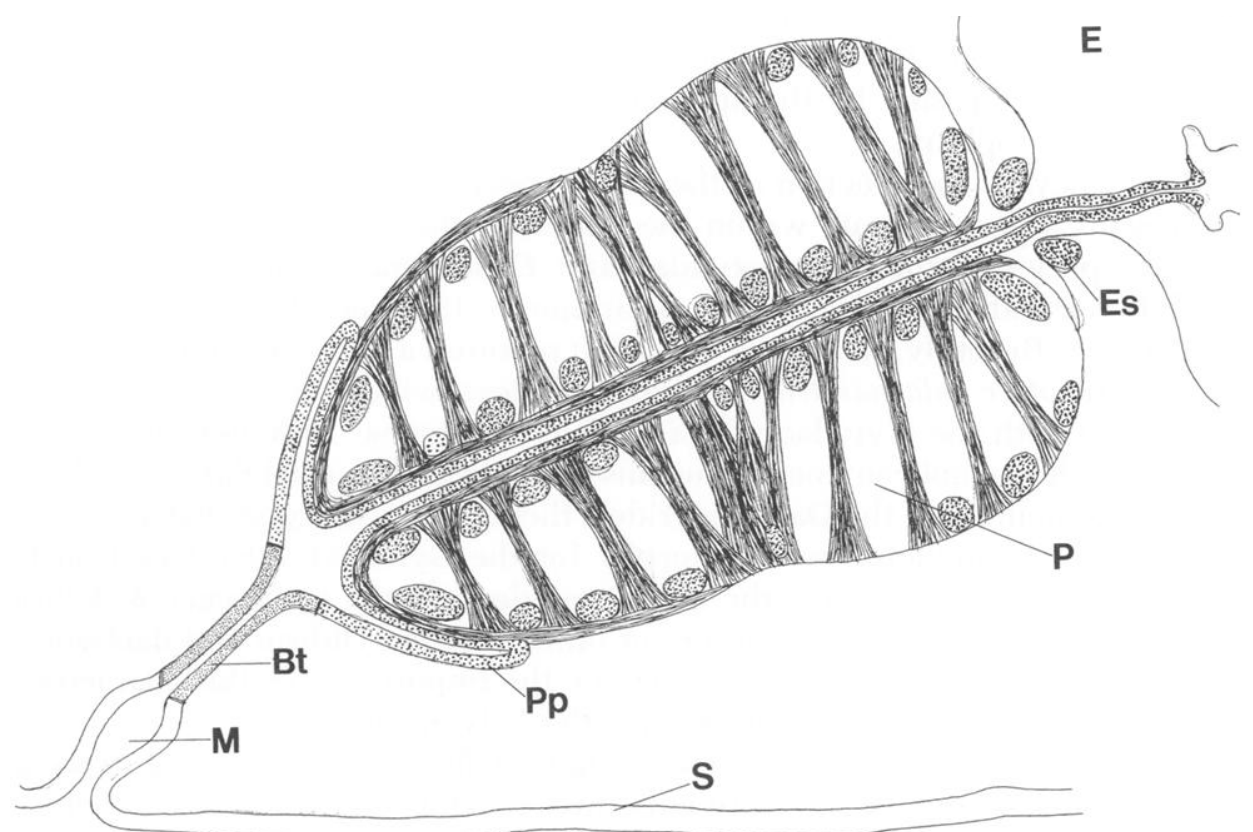

FIG. 6. Diagram of the midsagittal section of the pharyngeal area (foregut) in Gyrodactylus eucaliae (redrawn from Kritsky, 1971). Bt, buccal tube; E, esophagus; Es, esophageal sphincter; M, mouth; P, pharynx; Pp, prepharynx; S, somatic tegument.

electron-lucent fibrous content that included occasional concentrically arranged membranes near one pole.

Sparse rough endoplasmic reticulum (RER) with moderately dilated cisternae occurred predominantly in the basal portion of the syncytium in G. eucaliae (Fig. 3); RER was more widespread in the gastrodermis of Gyrodactylus sp. where it also occurred just beneath the luminal surface of the syncytium. Small Golgi complexes, consisting of 2-5 closely parallel elongate sacs and a series of lateral vesicles, were generally basal. The lateral sacs of each Golgi contained a moderately dense substance similar in appearance to the contents of the $V_{1}$ cytoplasmic vesicle. Rod-shaped mitochondria with tubular cristae occurred in moderate density near the base and were less dense in other regions of the gastrodermis (Fig. 2).

\section{DISCUSSION}

Bogitsh (1993) subdivided the digestive tract of monogenoideans into foregut and cecal regions, the latter of which is lined [sic] with gastrodermis. The ultrastructural organization of the gastrodermis of the Gyrodactylus species is reflective of its presumed function of digestion. Its luminal surface possesses lamellae which, although relatively few and widely spaced, apparently increase surface area for absorption. Within the gastrodermis, mitochondria, Golgi com- 
plexes, and RER are present suggesting a secretory function, perhaps, effecting formation of the $V_{1}$ cytoplasmic vesicles. That the contents of these vesicles may play a role in digestion, or intrasyncytial use or modification of absorbed nutrients, is suggested by the apparent release of their contents into the gastrodermal cytoplasm.

The syncytial construction of the gut of species of Gyrodactylus apparently represents a derived state within the Polyonchoinea. A cellular gut is known within species of the Monocotylidea and Euzetrema (a taxon of uncertain evolutionary affinity) (see Halton \& Stranock, 1976 and Fournier, 1978, respectively). Recently, Kritsky et al. (1993) reported a monolayered cellular gut in Lagarocotyle salamandrae (Lagarocotylidea), which has a sister-group relationship with the Gyrodactylidea + Dactylogyridea. Although his electron micrographs are not convincing, Junchis (1988) reported a cellular gut in Tetraonchus, a member of the Dactylogyridea; these findings suggest that a syncytial gut may be a predicted synapomorphy for the Gyrodactylidea based on the phylogenetic hypothesis for the Monogenoidea offered by Boeger \& Kritsky (1993). Studies on the fine structure of other gyrodactylidean and dactylogyridean taxa will be necessary to determine the importance of this character in developing evolutionary hypotheses for the Polyonchoinea.

According to Bogitsh (1993), the foregut of flatworms consists of "specializations" (suckers, increased musculature, secretory cells, sensory structures, and a pharynx) that aid in ingestion and food processing. Bogitsh (1993) stated that the lining of the foregut in monogenoideans "is an extension of the general body covering, demarcated from the gastrodermis by a pronounced junction." This generalization, however, does not apply to species of Gyrodactylus, wherein we also found a septate junction joining the epithelial lining of the pharynx to the gastrodermis within the esophagus (Fig. 4). In species of Gyrodactylus, the pharyngeal lining is neither continuous with nor an extension of the somatic tegument (Fig. 6). Kritsky (1971) reported that in G. eucaliae the region of the digestive system defined as "foregut" by Bogitsh (1993) consists of a mouth, a buccal tube, a prepharynx, a glandular and muscular pharynx, and esophageal glands. The mouth (usually apparent as a small surface indentation) is lined with the uninterrupted somatic tegument that is joined by a septate junction to a separate distinctive and continuous visceral epithelium lining the buccal tube. The prepharynx, pharynx, and anterior esophagus are lined with still another distinct and confluent visceral epithelium that connects with the internal boundary of the buccal tube and the gastrodermis within the esophagus by septate junctions (Kritsky, 1971; nobis). If indeed the lining of the foregut in other flatworms with digestive systems is a continuum of the somatic tegument, as suggested in Bogitsh's (1993) review, then the configuration found in the foregut segments of species of Gyrodactylus is reflective of several derived and perhaps autapomorphic characteristics for the genus.

\section{Literature Cited}

Boeger, W. A. \& Kritsky, D. C. 1993. Phylogeny and a revised classification of the Monogenoidea Bychowsky, 1937 (Platyhelminthes). Syst. Parasitol., 26: 1-32. 
Bogitsh, B. J. 1993. A comparative review of the flatworm gut with emphasis on the Rhabdocoela and Neodermata. Trans. Am. Microsc. Soc., 112: 1-9.

Dike, S. C. 1967. Ultrastructure of the ceca of the digenetic trematodes Gorgodera amplicava and Haematoloechus medioplexus. J. Parasitol., 53: 1173-1185.

FourniER, A. 1978. Euzetrema knoepffleri: Evidence for a synchronous cycle of the gastrodermal activity and an 'apocrine-like' release of the residues of digestion. Parasitology, 77: 19-26.

Halton. D. W. \& IEnNings. I. B. 1965. Observations on the nutrition of monogenetic trematodes.

of Syndesmis franciscana (Turbellaria: Rhabdocoela). Can. J. Zool., 53: 536-549.

JUNCHIS, L. A. 1988. Fine structure of the gastrodermis of Tetraonchus monenteron (Monogenea, Tetraonchidae). Tr. Zool. Inst. Akad. Nauk SSSR, 177: 117-124.

Kritsky, D. C. 1971. Studies on the fine structure of the monogenetic trematode Gyrodactylus eucaliae Ikezaki and Hoffman, 1957. Ph.D. Thesis, Univ. of Illinois, Urbana, Illinois. 530 pp.

Kritsky, D. C., Hoberg, E. P. \& Aubry, K. B. 1993. Lagarocotyle salamandrae n. gen., n. sp. (Monogenoidea, Polyonchoinea, Lagarocotylidea $\mathrm{n}$. ord.) from the cloaca of Rhyacotriton cascadae Good and Wake (Caudata, Rhyacotritonidae) in Washington State. J. Parasitol., 79: $322-330$.

Kritsky, D. C. \& Kruidenier, F. J. 1976. Fine structure and development of the body wall in the monogenean, Gyrodactylus eucaliae Ikezaki and Hoffman, 1957. Proc. Helminthol. Soc. Wash., 43: 47-58.

ROHDE, K. 1971. Untersuchungen an Multicotyle purvisi Dawes, 1941 (Trematoda: Aspidogastrea). VII. Ultrastruktur des Caecums der freien Larve und der geschlechtsreifen Form. Zool. Jahrb. Abt. Anat. Ont. Tiere, 88: 406-420.

1980. Some aspects of the ultrastructure of Gotocotyla secunda and Hexostoma euthynni. Ang. Parasitol., 21: 32-48. 